\title{
Associations of co-occurring psychosocial and lifestyle factors with multisite musculoskeletal pain during late adolescence-A birth cohort study
}

\author{
Heikkala, Eveliina
}

2019-09

Heikkala , E , Paananen, M , Taimela , S , Auvinen , J \& Karppinen , J 2019 , ' Associations of co-occurring psychosocial and lifestyle factors with multisite musculoskeletal pain during late adolescence-A birth cohort study ', European Journal of Pain , vol. 23 , no. 8 , pp. 1486-1496 . https://doi.org/10.1002/ejp.1414

http://hdl.handle.net/10138/318905

https://doi.org/10.1002/ejp.1414

acceptedVersion

Downloaded from Helda, University of Helsinki institutional repository.

This is an electronic reprint of the original article.

This reprint may differ from the original in pagination and typographic detail.

Please cite the original version. 


\section{Associations of Co-occurring Psychosocial and Lifestyle Factors with Multisite Musculoskeletal Pain during Late Adolescence - A birth Cohort Study}

Eveliina Heikkala ${ }^{1,2}$, Markus Paananen ${ }^{1}$, Simo Taimela ${ }^{3,4}$, Juha Auvinen ${ }^{1,5}$, Jaro Karppinen ${ }^{1,6,7}$.

\footnotetext{
${ }^{1}$ Medical Research Center Oulu, University of Oulu and Oulu University Hospital, Oulu, Finland

${ }^{2}$ Rovaniemi Health Center, Rovaniemi, Finland

${ }^{3}$ Department of Orthopedics and Traumatology, Helsinki University Hospital, Töölö hospital, Helsinki, Finland

${ }^{4}$ Clinicum, Department of Orthopedics and Traumatology, University of Helsinki, Helsinki, Finland

${ }^{5}$ Oulunkaari Health Center, Ii, Finland

${ }^{6}$ Center for Life Course Health Research, University of Oulu, Finland

${ }^{7}$ Finnish Institute of Occupational Health, Oulu, Finland
}

\section{Correspondence:}

Eveliina Heikkala

Medical Research Center Oulu, University of Oulu and Oulu University Hospital, PO Box 5000, 90014 University of Oulu, Finland.

Tel: +358405789748; fax: +358304746110

mia.heikkala@oulu.fi

\section{Funding sources}

None.

\section{Conflicts of interest}

None.

This article has been accepted for publication and undergone full peer review but has not been through the copyediting, typesetting, pagination and proofreading process, which may lead to differences between this version and the Version of Record. Please cite this article as doi: $10.1002 /$ ejp. 1414

This article is protected by copyright. All rights reserved. 


\begin{abstract}
Background: Musculoskeletal (MS) pain is common. It often exists in several sites and is recurrent. Psychosocial difficulties and unhealthy behaviours have been related to multisite MS pain, but no literature has assessed the impact of accumulated psychosocial and lifestyle factors on recurrent multiple MS pain.

Methods: Our data was gathered from two questionnaires of the well-known Northern Finland Birth Cohort 1986 (NFBC1986), sent to members when they were aged 16 and 18. A total of 1625 adolescents ( 712 boys and 913 girls) answered questions on smoking, physical activity, sedentary behaviour, sleeping, and emotional and behavioural problems at 16 years and on musculoskeletal pain at 16 and 18 years. Weight and height measurements were taken at a health examination at baseline. A latent class analysis (LCA) and multinomial regression analysis were conducted.
\end{abstract}

Results: We identified four clusters among both sexes. "Externalizing behavior" among both genders (OR 2.98, CI 1.73-5.13 among boys; OR 2.38, CI 1.38-4.11 among girls), "Multiple risk behaviors" among girls (OR 2.73, CI 1.30-5.71) and a "Sedentary" cluster among boys (OR 1.85, CI 1.21-2.82) were associated to recurrent multisite MS pain. 'Obese' clusters had no significant associations with recurrent multiple MS pain.

Conclusions: Adolescents with psychosocial difficulties and/or several adverse health behaviours were at an increased risk of recurrent multisite MS pain, which emphasizes the importance of simultaneously studying multiple rather than single factors. The identification of risk groups may help more accurately target preventive interventions.

Significance: This study found subgroups of adolescents at risk of recurrent multisite musculoskeletal pain during late adolescence. The accumulation of multiple adverse behaviours is likely to provide new perspectives for understanding the multidimensional nature of multiple MS pains.

\title{
1. Introduction
}

In the last decade, musculoskeletal (MS) research has shifted its emphasis from single-site pain to multisite pain (Carnes et al. 2007, Kamaleri et al. 2008a). Large epidemiological studies have defined multisite MS pain as pain occurring concurrently in different body parts, including the back, neck and lower limbs (Carnes et al. 2007, Kamaleri et al. 2008b, Paananen et al. 2010a). Multisite MS pain seems to have more detrimental consequences for health-related quality of life (Holm et al. 2012, Paananen et al. 2011), pain disability (Hoftun et al. 2011, Holm et al. 2012) and function (Bruusgaard et al. 2012), and appears to be more recurrent/persistent (El-Metwally et al. 2004) than single site pain already among the young. 
Between 22\% and $69 \%$ of European adolescents report multisite MS pain (Hanvold et al. 2016, Paananen et al. 2010a, Pellisé et al. 2009). Generally, adolescent MS pain often has a non-specific characteristic, with no identifiable patho-anatomical cause (Houghton 2010, MacDonald et al. 2017). Pains with addressable aetiology are mainly related to an acute injury or overuse of the MS system rather than to degenerative processes (MacDonald et al. 2017).

Adolescence is a critical stage of life during which health risk behaviours and psychosocial problems tend to emerge (Corder et al. 2017, Costello et al. 2011). Part of these engagements seem to be related to external stimuli to which adolescent brains are especially vulnerable (Casey et al. 2008). Earlier longitudinal studies have found that different health behaviours and psychosocial factors influence the development of multisite pain in childhood and adolescence. For instance, an English study observed that psychosocial symptoms and high levels of physical activity between the ages of 11 and 14 predicted widespread pain (WSP) one year later (Jones et al. 2003), while a Finnish study found that depressive feelings among 10- to 12-year-olds predicted onset of WSP at one- and four-year follow-ups (Mikkelsson et al. 2008). Furthermore, sleep problems at 15 years predicted WSP two years later among English adolescents (Harrison et al. 2014).

We have previously shown that instead of one, adolescents often struggle with several adverse psychosocial and health-related behaviours at the same time (Heikkala et al. 2014). Later we have found that clustered unhealthy habits are associated with low back pain (Mikkonen et al. 2016). In terms of adolescent multisite MS pain, the number of psychosocial problems, unhealthy lifestyle factors and multiple MS pain sites seemed to have a doseresponse relationship in a cross-sectional setting (Paananen et al. 2010a), and several of these single factors associated with recurrent MS pain longitudinally among the participants of the Northern Finland Birth Cohort 1986 (NFBC1986) (Jussila et al. 2014, Paananen et al. 2010b). 
However, it remains unknown whether different combinations of these factors specifically increase the risk of recurrent multisite pain. Thus, the aim of this study was to examine how earlier formed lifestyle and psychosocial patterns (Heikkala et al. 2014) associate with recurrent multiple MS pain among adolescents in a two-year follow-up. Our hypothesis was that subgroups with psychosocial problems in particular would be likely to suffer recurrent multisite MS pain. Our analyses were stratified by gender, as the prevalence of MS pain differs among boys and girls.

\section{Methods}

\subsection{Study population}

The study population consisted of participants of the Oulu Back Study (OBS) in 2003-2004 who belonged to the Northern Finland Birth Cohort 1986 (NFBC1986) between 2001 and 2002. The OBS included NFBC1986 members living within $100 \mathrm{~km}$ from the city of Oulu at the age of 18 to 19 . The NFBC1986 itself consists of those born in the northernmost provinces of Finland between 1st July 1985 and 30th June 1986 (n=9479). We collected the baseline data of our work via a postal survey of NFBC1986 participants aged 15 to 16, over a period of 11 months, from May 2001 to April 2002 (n=9215, of which 7344 replied and 6892 provided data on lifestyle and psychosocial factors). We also used a postal questionnaire for the follow-up sample of the OBS participants $(n=2969$, of which 2012 replied). A total of 1583 (691 boys and 892 girls) adolescents had taken part in the baseline collection of data on lifestyle factors, psychosocial problems and multisite MS pain and responded to the second questionnaire on multisite MS pain. All the participants gave their informed consent, and the study was approved by the local ethics committees.

This article is protected by copyright. All rights reserved. 


\subsection{Psychosocial problems at 16 years}

The Youth Self-Report (YSR) questionnaire is a widely used instrument for assessing adolescents' emotional and behavioural problems. The questionnaire comprises 105 items, each of which ask the respondents to rate themselves on a scale of $0-2: 0=$ not true, $1=$ somewhat or sometimes true, and 2 = very true or often true. From these items, eight syndrome scales can be formed, of which anxious/depressed symptoms, withdrawn/depressed symptoms and somatic complaints can be scored as "internalizing syndromes", and rulebreaking behaviour and aggressive behaviour as "externalizing syndromes". We used these broadband scales in the present work, and trichotomized them as normal range, borderline range and clinical range, consistent with the recommended cut-off limits. For further analyses, we combined the last two groups as "problem range" (above $82^{\text {nd }}$ percentile) (Helstelä and Sourander, 2001, Kantomaa et al. 2008). The documentation of the construct, criterion-related and content validity, and the reliability of the YSR, based on the test-retest correlations, have proven to be good (Achenbach and Rescorla, 2001), and the questionnaire is an established reliable data collection method in epidemiological studies in Scandinavia (Berg-Nielsen et al. 2003, Broberg et al. 2001) and Finland (Helstelä and Sourander, 2001).

\subsection{Lifestyle factors at 16 years}

\section{Physical activity}

The questionnaire asked adolescents to estimate their participation in brisk (=at least some sweating and shortness of breath) moderate-to-vigorous physical activity (MVPA) outside school hours (Tammelin et al. 2007). Those who reported more than three hours of MVPA per week were classified as active, 2-3 hours of MVPA per week as moderately active, and 1 hour or less of MVPA per week as inactive. 


\section{Smoking}

Three questions elicited smoking behaviour: "Have you ever smoked?", "Have you ever smoked regularly?" and "How much do you currently smoke?". From the responses we formed three categories: (1) non-smokers, (2) 0.1-1.0 pack-years by the age of 16 years, and (3) over 1.0 pack-year, where one pack-year is equivalent to 15 cigarettes smoked per day for a year.

\section{Sedentary behaviour}

We measured sedentary behaviour by inquiring about the adolescents' daily time spent watching television, reading books or magazines, playing or working on a computer, and other sedentary activities. For girls, we retained the total number of sedentary hours as a continuous variable and for boys as a trichotomized variable: (1) 4 hours or less per day, (2) 4.1-7.9 hours, and (3) 8 hours or more per day.

\section{Sleeping time}

The sleep variable was based on responses to the question: "How many hours on average do you sleep per day?", and the categories included: (1) less than 8 hours, (2) 8-9 hours, and (3) more than 9 hours per day.

\section{Body mass index}

The adolescents' weight and height measurements were taken at a health examination at the age of $16(n=6068$, participation rate $88 \%)$. We calculated BMI values according to the

following formula: weight $(\mathrm{kg}) /$ height (meters) $)^{2}$. We used self-reported values for the $12 \%$ of adolescents who did not participate in the health examination. A continuous variable was formed for BMI. The International Obesity Task Force age-specific cut-off points for BMI 
provided scales for overweight: $23.90-28.88 \mathrm{~kg} / \mathrm{m}^{2}$ for boys and $24-29.43 \mathrm{~kg} / \mathrm{m}^{2}$ for girls, and for obesity: $28.88 \mathrm{~kg} / \mathrm{m}^{2}$ for boys and $29.43 \mathrm{~kg} / \mathrm{m}^{2}$ for girls (Cole et al. 2000).

\section{Confounding factor}

As family socioeconomic status has been linked to both health behaviour and mental distress, we regarded it as a possible confounder. Information on parent's occupational status, which characterized family socioeconomic status, was collected at 16 years via a questionnaire sent to parents. We categorized occupational status as 1) higher clerical employees; 2) selfemployed; 3) lower clerical employees; 4) workers, and 5) students, pensioners, unemployed or unknown.

\subsection{Categorization of the variables used in clustering}

In the procedure for selecting continuous and categorical variables for LCA, we evaluated several different combinations of continuous and categorical, i.e. dichotomized and trichotomized, variables. Dichotomizing problems other than externalizing and internalizing problems would have led to information loss and would have complicated interpretability, whereas using all the variables as continuous variables resulted in small group sizes. Finally, the model, in which externalizing and internalizing were dichotomized; physical activity level, sleeping time, smoking among both genders and sedentary activity among boys were trichotomized; and BMI in both sexes and sedentary activity variable among girls were used as continuous variables was the most representative of our data and had the least information loss. (Heikkala et al. 2014)

This article is protected by copyright. All rights reserved. 


\subsection{Multisite musculoskeletal pain}

Musculoskeletal pain was elicited via the question "Have you had any aches or pains during the last six months in the following areas of your body?" (1) neck or occipital area, (2) shoulders, (3) low back, (4) elbows, (5) wrists, (6) knees, and (7) ankle-foot area, at both 16 and 18 years. We combined the last four as peripheral pain. The adolescents provided answers of (1) no, (2) yes, but I have not consulted a physician, physiotherapist, nurse or other health professional (regarded as reporting pain), or (3) yes, and I have consulted a physician, physiotherapist, nurse or other health professional (regarded as consultation for pain). We established four groups on the basis of the number of pain sites: (1) no pain, (2) pain in one site, (3) pain in two sites, and (4) pain in three to four sites. In the analyses of the recurrence of multisite pains, we combined Groups 3 and 4 due to small numbers. We also merged the response options "reporting MS pain" and "consultation for MS pain". Two or more pain sites at the age of 16 and 18 was defined as recurrent multisite MS pain, which was the main outcome of this study.

\subsection{Statistical methods}

We assumed that lifestyle and psychosocial factors form different clusters, which present distinct patterns of these factors. To study these patterns, we carried out latent class analysis (LCA), which is an established cluster analytic approach. LCA helps in understanding the complex heterogeneity of the studied factors in the study population by identifying the smallest number of unobserved subgroups of individuals on the basis of psychosocial and lifestyle response patterns. In LCA, the number of latent clusters is increased until the most appropriate model is found. We added the clusters to the model of seven different subgroups. The selection of the most suitable latent cluster number model was based on multiple statistical criteria (Table 1), of which we preferred low BIC value (see Heikkala et al. 2014). 
We applied multinomial regression analysis to study the associations between clusters and recurrent MS pain, stratified by gender. We used lifestyle and psychosocial patterns as explanatory factors and multisite MS pain at 16 and 18 years as the outcome factor. We adjusted the associations for socioeconomic status. Odds ratios (ORs) with 95\% confidence intervals (CI) described the strengths and statistical significances of the possible associations. We used the Chi square $\left(\mathrm{x}^{2}\right)$ test to estimate the statistical significance in the representativeness analyses.

\section{Results}

Representativeness of the study sample

We used the OBS subsample of the original NFBC1986 cohort to evaluate the recurrence of multisite MS pain. A comparison of the OBS subjects and the remaining NBFC1986 members revealed that a slightly lower proportion of the OBS participants were boys ( $44 \% \mathrm{vs}$ $49 \%, \mathrm{p}<0.001 ; \mathrm{x}^{2}$ test) and a higher percentage of their parents worked as lower clerical employees $(20 \%$ vs $13 \%, p<0.001)$. Sitting less than four hours per day $(29 \%$ vs $26 \%$, $\mathrm{p}<0.05)$ and non-smoking ( $84 \%$ vs $81 \%, \mathrm{p}=0.001)$ were more prevalent among the OBS participants than among the other NFBC1986 adolescents. We observed no significant differences in the prevalence rates of emotional and behavioural problems, physical activity level, weight status, sleeping time, or multisite MS pain.

This article is protected by copyright. All rights reserved. 


\subsection{Class characteristics}

We fit the latent class model of four clusters to the adolescents' data on lifestyle behaviours and psychosocial problems (Heikkala et al. 2014; Table 1).

Among the boys, Externalizing behavior (Cluster 1; 14\% of boys) represented quite physically active adolescents with externalizing and internalizing problems and the highest probability of smoking (Fig. 1). The boys in the Sedentary cluster (Cluster 2; 27\%) were the most physically inactive and sedentary and had the shortest sleeping time. The Obese cluster (Cluster 3; 8\%) comprised boys with a very high BMI. These were also quite inactive. Participants belonging to the Reference subgroup (Cluster $4 ; 51 \%$ ) engaged in the most favourable lifestyle and had the lowest probability of psychosocial problems.

Among the girls, the Externalizing behavior cluster (Cluster 1; 15\% of girls) consisted of the least inactive young people, who also reported externalizing problems (Fig. 2). They also had a relatively high probability of internalizing problems and smoking. All adverse lifestyle factors, except obesity and psychosocial problems, were concentrated in the Multiple risk behaviors cluster (Cluster 2; 12\%). The Obese cluster (Cluster 3; 7\%) was formed of girls with a high BMI and low physical activity levels. The lowest probabilities of psychosocial problems, smoking, overweight and poor sleeping characterized the Reference cluster (Cluster 4; 67\%).

\subsection{Prevalence of musculoskeletal pain}

Seventeen per cent of the girls and $32 \%$ of the boys had been pain-free during the preceding six months at 16 years (Table 2). At 18 years, the percentages were similar: $8 \%$ for the girls and $24 \%$ for the boys. Two or more pain sites occurred among two-fifths of the boys and three-fifths of the girls at baseline, and among three-fifths of the boys and four-fifths of the 
girls at follow-up. Three to four pains were the most prevalent in the girl clusters at 16 years, whereas the boy clusters had more variability (Table 3 ).

\subsection{Recurrence of multisite pain in clusters}

In all the girl clusters, over half reported having had multiple MS pains at the ages of 16 and 18, while among the boys, $52 \%$ of the Externalizing behavior cluster, $36 \%$ of the Sedentary cluster, $38 \%$ of the Obese cluster and $25 \%$ of the Reference cluster suffered from multisite

pain at baseline and follow-up (Table 4). The prevalence of "no pain" or "one-site pain" at the age of 16 and 18 varied from $11 \%$ to $21 \%$ among the girls, and from $32 \%$ to $48 \%$ among the boys.

In the analyses, the Reference clusters were used as "Reference" as they represented the most favourable patterns of lifestyle and psychosocial factors. Belonging to the Externalizing behavior cluster was related to recurrent multisite pain among both genders with nearly threefold odds (OR 2.98, CI 1.73-5.13; Table 5) among the boys and over two-fold odds (OR 2.38, CI 1.38-4.11) among the girls. Girls belonging to the Multiple risk behavior cluster had similar levels of odds of suffering recurrent multiple pain (OR 2.73, CI 1.30-5.71). We also observed a significant association between the Sedentary cluster and recurrent multisite MS pain among the boys (OR 1.85, CI 1.21-2.82). Belonging to the Obese clusters was not statistically significantly related to pains.

\section{Discussion and conclusions}

We examined the roles of lifestyle and psychosocial clusters in recurrent multisite MS pain between the ages of 16 and 18 in a birth cohort. LCA revealed four clusters for both genders at the age of 16 . The accumulation of emotional and behavioural problems, smoking and physical activity significantly increased the risk of recurrent multisite MS pain among both 
genders. In addition, having problems in several areas among the girls and inactive lifestyle among the boys associated considerably with recurrent multiple MS pains.

A significant number of the adolescents (one third of the boys and over a half of the girls) suffered from recurrent multisite MS pain. Similar findings have been observed among a sample of Norwegian university students, as $47 \%$ of the population reported persistent multiple pains in different MS locations during a 6.5-year follow-up (Hanvold et al. 2016). Among 7 to 18 -year-old American children and adolescents with diagnosed chronic pain (of which most was MS pain), $63 \%$ characterized the pain as occurring in multiple sites (Basch et al. 2018). In contrast, studies by Mikkelsson et al. (1999, 2008) found that WSP persisted among only $0.7 \%$ and $28 \%$ of children, depending on the measured time point. Harrison et al. (2014) have also observed low levels of chronicity of WSP (4\% of adolescents). Regarding other combinations of MS and other pains, one fourth of adolescents seem to experience persistent symptoms (Hoftun et al. 2011, Kröner-Herwig et al. 2011, van Gessel et al. 2011).

The clusters with a high number of accumulated detrimental psychosocial and lifestyle factors were at a higher risk of recurrent multisite MS pain than the favourable lifestyle factor subgroups, which is in line with earlier cross-sectional observations (Paananen et al. 2010a). Hoftun et al. (2012) noticed in their study that the probability of chronic pain rose in accordance with an increasing number of unfavourable lifestyle factors, whereas McBeth et al. (2001) discovered the same in terms of the prevalence of persistent chronic widespread pain and multiplying psychosocial risks. However, the odds ratios of our results did not quite reach the same levels as previously when we added the single-factor influences one by one (Paananen et al. 2010a). In Paananen et al.'s study, however, the researchers decided which factors to use, whereas LCA forms natural clusters from the available lifestyle and psychosocial variables.

This article is protected by copyright. All rights reserved. 
Psychosocial symptoms and mental health, in a broad sense, are likely to play a significant role in the transformation from acute to chronic MS pain (Pincus et al. 2002) and the persistence of MS pain itself (Paananen et al. 2010b, Skrove et al. 2015). This can also be seen in our work as externalizing and internalizing problems, accumulated in three of four subgroups at risk of continuing multiple MS pain. Behavioural difficulties were particularly prevalent among the risk profiles. It is also worth noticing that smoking prevalence was somewhat high and inactivity levels quite low among the Externalizing behavior adolescents, particularly physical inactivity among the girls. McLaren et al. (2017) found that adolescents suffering from problematic MS pain (most of which was multisite pain), smoked more and had poorer mental health than those with no pain, which is in concordance with current observations. Previously, Eckhoff and Kvernmo (2014) have connected over eight hours of physical activity per week to multisite MS pain in adolescence, Puroila and co-workers (2015) have linked moderate levels of activity to later multiple MS pain, and Jones et al. (2003) have found associations between psychosocial problems and high physical activity and widespread pain among schoolchildren, lending some support to our findings. Extreme sports with aggressive characteristics are considered a potential explanation for clustering (Heikkala et al. 2014) and have been linked to MS pain (Guddal et al. 2017), but a more precise analysis of the subscales of psychosocial symptoms observed no disparities in the Externalizing behavior clusters (data not shown).

Inactive lifestyle, including sedentary behaviour and physical inactivity, appears to be related to multisite MS pain. A study by Kamaleri et al. (2008b) noticed a number of pain sites that were higher among individuals with low physical activity, and Eckhoff and Kvernmo (2014) reported sedentary activity as having a similar impact. Haukka et al. (2012) also found that moderate or low physical activity predicted persistent MS pains among adults, but reverse findings have been published among adolescents, i.e. an 
association between sedentary behaviour and persistent multisite MS pain has been observed but no significant relations between physical inactivity and persistent multiple MS pains has been found (Paananen et al. 2010b). In the current work, low physical activity and sedentary behaviour accumulated among boys and formed a risk group of their own, i.e., the Sedentary cluster. Interestingly, sleep time was also the shortest on average among these boys. Sleeping might be a critical factor that increases the risk of pain among Sedentary boys (Bonvanie et al. 2016, Gupta et al. 2007, Harrison et al. 2014). Among girls, inactivity and poor sleep was mostly concentrated in the Multiple risk behavior cluster, in which the girls were also at a high risk of recurrent MS pains, as discussed above.

Obesity did not influence the risk of recurrent multiple MS pains in the present study. Supporting our result, obesity was related to any pain, but not chronic widespread pain among 3376 British adolescents (Deere et al. 2012). In a Norwegian study, both overweight and obesity associated with chronic multisite pain (Hoftun et al. 2012). These differences might be due to different definitions, as Hoftun et al. (2012) defined multisite pain as pain in the stomach, head and the MS system. It might also be that the effects of overweight and obesity take longer to emerge in multiple MS sites, as adolescent obesity has been related to later adulthood multisite MS pain (Puroila et al. 2015).

The main strength of the present study is its large baseline sample of adolescents, which can be considered representative of Finnish young people. In addition, according to our best knowledge, no study has previously analysed the influence of LCA clusters on recurrent multisite MS pain. Furthermore, the method we used is established in the field of cluster analyses (Collins and Lanza, 2010, Lazarsfeld and Henry, 1986), and provides a more nuanced understanding of the participants' lifestyle than traditional analytic approaches. 
The relatively small follow-up population, a sub-cohort based on location, is likely to be a weakness in our work, as in some clusters the amount of certain pain statuscharacterized participants ranged from only 8 to 10 . In addition, recurrent multisite MS pain was regarded as pain occurring at the age of 16 and 18 during the six months before the measurement points. Thus, when interpreting our results, it must be borne in mind that no information on the pain situation was available between these time points, and some participants may have suffered pain at only these ages but not in between. We did not study pain intensity or frequency, and this must also be considered a weakness of our study. Furthermore, we do not know whether adolescents had pain in different or the same MS locations at the measured time points. However, our focus in this study was on multisite MS pain in general. Self-reported pain values have been criticized as unreliable. However, the previous literature has widely used self-reporting, and no objective measurement methods are yet available to estimate pain status. We did not explore the influences of single factors in the current study, thus we were unable to compare the role of single factors and LCA grouping in multisite MS pain.

In conclusion, the results of the present study provide further support for previous observations regarding the relationships between lifestyle and psychosocial factors and recurrent multisite MS pain among adolescents. We found that the risk of recurrent multiple MS pain was higher among those with psychosocial difficulties and/or several adverse health behaviours, and it seems that these associations are strong. As a result, our findings emphasize the importance of an assessment of psychosocial and lifestyle factors concurrently among adolescents with multisite MS pain. However, due to limited data on pain characteristics, the clinical relevance of the studied pain problems may be questioned, 
and therefore, future research should verify the current findings in different populations and especially in data that also includes information on consequential pain.

\section{Acknowledgements}

No acknowledgements.

\section{Author contributions}

EH participated in the study design, calculated the statistics, interpreted the results and wrote the first draft of the manuscript; MP, ST, JA and JK took part in study planning, critically revised the manuscript, provided suggestions to improve the manuscript and supervised the study process. All authors have seen and approved the final version.

\section{References}

Achenbach,T.M., Rescorla, L.A. (2001). Manual for the ASEBA School age forms and profiles. Burlington: University of Vermont, Research Center for Children, Youth and Families.

Basch M.C., Chow E.T., Logan D.E., Borsook D., Schechter N.L., Simons L.E. (2018). Cumulative effects of multiple pain sites in youth with chronic pain. Eur J Pain, 22, 1134-1141. doi:10.1002/ejp.1201

Berg-Nielsen, T.S., Vika, A., Dahl, A.A. (2003). When adolescents disagree with their mothers: CBCL-YSR discrepancies related to maternal depression and adolescent self-esteem. Child Care Health Dev, 29, 207-213.

Bonvanie, I.J., Oldehinkel, A.J., Rosmalen, J.G.M., Janssens, K.A.M. (2016). Sleep problems and pain: a longitudinal cohort study in emerging adults. Pain, 157, 957-963. http://doi.org/10.1097/j.pain.0000000000000466

Broberg, A.G., Ekeroth, K., Gustafsson, P.A., Hansson, K., Hagglof, B., Ivarsson, T., Larsson, B. (2001). Selfreported competencies and problems among Swedish adolescents: a normative study of the YSR. Eur Child Adolesc Psychiatry, 10, 186-193.

Bruusgaard, D., Tschudi-Madsen, H., Ihlebaek, C., Kamaleri, Y., Natvig, B. (2012). Symptom load and functional status: results from the Ullensaker population study. BMC Public Health, 12, 1085.

Casey, B.J., Getz, S., Galvan, A. (2008). The adolescent brain. Dev. Rev. 28, 62-77.

Carnes, D., Parsons, S., Ashby, D., Breen, A., Foster, N.E., Pincus, T. (2007). Chronic musculoskeletal pain rarely presents in a single body sites: Results from a UK population study. Rheumatology (Oxford) 46, 11681170.

Cole, T.J., Bellizzi, M.C., Flegal, K.M., Dietz, W.H. (2000). Establishing a standard definition for child overweight and obesity worldwide: international survey. $B M J, 320,1240-1243$.

This article is protected by copyright. All rights reserved. 
Collins, L.M., Lanza, S.T. (2010) Latent class and latent transition analysis: With applications in the social, behavioral, and health sciences. New York, NY: Wiley.

Corder K., Winpenny E., Love R., Brown H.E., White M., van Sluijs E. (2017) Change in physical activity from adolescence to early adulthood: a systematic review and meta-analysis of longitudinal cohort studies. $\mathrm{Br} J$ Sports Med, 0, 1-9. doi:10.1136/bjsports-2016-097330

Costello E.J., Copeland W., Angold A. (2011) Trends in psychopathology across the adolescent years: What changes when children become adolescents and when adolescents become adults? J Child Psychol Psychiatry, 52, 1015-1025. doi:10.1111/j.1469-7610.2011.02446.x.

Deere, K.C., Clinch, J., Holliday, K., McBeth, J., Crawler, E.M., Sayers, A., Palmer, S., Doerner, R., Clark, E.M., Tobias, J.H. (2012). Obesity is a risk factor for musculoskeletal pain in adolescents: findings from a population-based cohort. Pain, 153, 1932-1938. http://doi.org/10.1016/j.pain.2012.06.006

Eckhoff, C., Kvernmo, S. (2014). Musculoskeletal pain in Arctic indigenous and non-indigenous adolescents, prevalence and associations with psychosocial factors: A population-based study. BMC Public Health, 14, 617.

El-Metwally, A., Salminen, J.J., Auvinen, A., Kautiainen, H., Mikkelsson, M. (2004). Prognosis of non-specific musculoskeletal pain in preadolescents: A prospective 4-year follow-up study till adolescence. Pain, 110, 550559. http://doi.org/10.1016/j.pain.2004.03.021

Guddal, M.H., Stensland, S.Ø., Småstuen, M.C., Johnsen, M.B., Zwart, J-A., Storheim K. (2017). Physical Activity Level and Sport Participation in Relation to Musculoskeletal Pain in a Population-Based Study of Adolescents: The Young-HUNT study. Orthop J Sports Med, 5, 2325967116685543. http://doi.org/10.1177/2325967116685543

Gupta, A., Silman, A.J., Ray, D., Morriss, R., Dickens, C., MacFarlane, G.J., Chiu, Y.H., Nicholl, B., McBeth, J. (2007). The role of psychosocial factors in predicting the onset of chronic widespread pain: results from a prospective population-based study. Rheumatology, 46, 666-671. http://doi.org/10.1093/rheumatology/kel363

Hanvold, T.N., Lunde, L.K., Koch, M., Waersted, M., Veiersted, K.B. (2016). Multisite musculoskeletal pain among young technical school students entering working life. BMC Musculoskelet Disord, 17, 82. http://doi.org/10.1186/s12891-016-0938-6

Harrison, L., Wilson, S., Munafò, M.R. (2014). Exploring the associations between sleep problems and chronic musculoskeletal pain in adolescents: a prospective cohort study. Pain Res Manag, 19, e139-e145.

Haukka, E., Ojajärvi, A., Takala, E-P., Viikari-Juntura, E., Leino-Arjas, P. (2012). Physical workload, leisuretime physical activity, obesity and smoking as predictors of multisite musculoskeletal pain. A 2-year prospective study of kitchen workers. Occup Environ Med, 69, 485-492. http://doi.org/10.1136/oemed-2011100453

Heikkala, E., Remes, J., Paananen, M., Taimela, S., Auvinen, J., Karppinen, J. (2014). Accumulation of lifestyle and psychosocial problems and persistence of adverse lifestyle over two-year follow-up among Finnish adolescents. BMC Public Health, 14, 542.

Helstelä, L., Sourander, A. (2001). Self-reported competence and emotional and behavioral problems in a sample of Finnish adolescents. Nord J Psychiatry, 55, 381-385.

Hoftun, G.B., Romundstad, P.R., Zwart, J-A., Rygg, M. (2011). Chronic idiopathic pain in adolescence--high prevalence and disability: the young HUNT Study 2008. Pain, 152, 2259-66. http://doi.org/10.1016/j.pain.2011.05.007

Holm, S., Ljungman, G., Söderlund, A. (2012). Pain in children and adolescents in primary care; chronic and recurrent pain is common. Acta Padiatrica, 101, 1246-1252. http://doi.org/10.1111/j.1651-2227.2012.02829.x

Houghton K.M. (2010). Review for the generalist: evaluation of low back pain in children and adolescents. Pediatric Rheumatology, 8, 28.

Jones, G.T., Silman, A.J., Macfarlane, G.J. (2003). Predicting the onset of widespread body pain among children. Arthritis Rheum, 48, 2615-2621. http://doi.org/10.1002/art.11221 
Jussila, L., Paananen, M., Näyhä, S., Taimela, S., Tammelin, T., Auvinen, J., Karppinen, J. (2014). Psychosocial and lifestyle correlates of musculoskeletal pain patterns in adolescence: a 2-year follow-up study. Eur J Pain, 18, 139-146. http://doi.org/10.1002/j.1532-2149.2013.00353.x

Kamaleri, Y.I., Natvig, B., Ihlebaek, C.M., Bruusgaard, D. (2008a). Localized or widespread musculoskeletal pain: does it matter? Pain, 138, 41-46.

Kamaleri, Y., Natvig, B., Ihlebaek, C.M., Bruusgaard, D. (2008b). Number of pain sites is associated with demographic, lifestyle, and health-related factors in the general population. Eur J Pain 12, 742-748. http://doi.org/10.1016/j.ejpain.2007.11.005

Kantomaa, M.T., Tammelin, T.H., Ebeling, H.E., Taanila, A.M. (2008). Emotional and behavioral problems in relation to physical activity in youth. Med Sci Sports Exerc, 40, 1749-1756. http://doi.org/10.1249/MSS.0b013e31817b8e82

Kröner-Herwig, B., Gassmann, J., van Gessel, H., Vath, N. (2011). Multiple pains in children and adolescents: A risk factor analysis in a longitudinal study. $J$ Pediatr Psychol, 36, 420-432. http://doi.org/10.1093/jpepsy/jsq099

Lazarsfeld, P.F., Henry, N.W. (1968). Latent Structure Analysis. Boston: Houghton Mifflin.

MacDonald J., Stuart E., Rodenberg R. (2017). Musculoskeletal Low Back Pain in School-aged Children. A Review. JAMA Pediatr. doi:10.1001/jamapediatrics.2016.3334

McBeth, J., Macfarlane, G.J., Hunt, I.M., Silman, A.J. (2001). Risk factors for persistent chronic widespread pain: a community-based study. Rheumatology, 40, 95-101.

McLaren, N., Kamper, S.J., Hodder, R., Wiggers, J., Wolfenden, L., Bowman, J., Campbell, E., Dray, J., Williams, C.M. (2017). Increased Substance Use and Poorer Mental Health in Adolescents With Problematic Musculoskeletal Pain. J Orthop Sports Phys Ther, 47, 705-711.

Mikkelsson, M., El-Metwally, A., Kautiainen, H., Auvinen, A., Macfarlane, G.J., Salminen, J.J. (2008). Onset, prognosis and risk factors for widespread pain in schoolchildren: a prospective 4-year follow-up study. Pain, 138, 681-687. http://doi.org/10.1016/j.pain.2008.06.005

Mikkelsson, M., Sourander, A., Salminen, J.J., Kautiainen, H., Piha, J. (1999). Widespread pain and neck pain in. schoolchildren. A prospective one-year follow-up study. Acta Paediatr, 88, 1119-1124.

Mikkonen, P., Heikkala, E., Paananen, M., Remes, J., Taimela, S., Auvinen, J., Karppinen, J. (2016). Accumulation of psychosocial and lifestyle factors and risk of low back pain in adolescence: a cohort study. Eur Spine J, 25, 635-642. http://doi.org/10.1007/s00586-015-4065-0

Paananen, M.V., Auvinen, J.P., Taimela, S.P., Tammelin, T.H., Kantomaa, M.T., Ebeling, H.E., Taanila, A.M., Zitting, P.J., Karppinen, J.I. (2010a). Psychosocial, mechanical, and metabolic factors in adolescents' musculoskeletal pain in multiple locations: A cross-sectional study. Eur $J$ Pain, 14, 395-401. http://doi.org/10.1016/j.ejpain.2009.06.003

Paananen, M.V., Taimela, S.P., Auvinen, J.P., Tammelin, T.H., Kantomaa, M.T., Ebeling, H.E., Taanila, A.M., Zitting, P.J., Karppinen, J.I. (2010b). Risk factors for persistence of multiple musculoskeletal pains in adolescence: a 2-year follow-up study. Eur J Pain, 14, 1026-1032. http://doi.org/10.1016/j.ejpain.2010.03.011

Paananen, M., Taimela, S., Auvinen, J., Tammelin, T., Zitting, P., Karppinen, J. (2011). Impact of SelfReported Musculoskeletal Pain on Health-Related Quality of Life among Young Adults. Pain Medicine, 12, 917.

Pellisé, F., Balague, F., Rajmil, L., Cedraschi, C., Aguirre, M., Fontecha, C.G., Pasarin, M., Ferrer, M. (2009). Prevalence of low back pain and its effect on health-related quality of life in adolescents. Arch Pediatr Adolesc Med, 163, 65-71. 
Pincus, T., Burton, A.K., Vogel, S., Field, A.P. (2002). A systematic review of psychological factors as predictors of chronicity/disability in prospective cohorts of low back pain. Spine, 27, E109-E120.

Puroila, A., Paananen, M., Taimela, S., Järvelin, M-R., Karppinen, J. (2015). Lifestyle-factors in adolescence as predictors of number of musculoskeletal pain sites in adulthood: a 17-year follow-up study of a birth cohort. Pain Med, 16, 1177-1185.

Skrove, M., Romundstad, P., Indredavik, M.S. (2015). Chronic multisite pain in adolescent girls and boys with emotional and behavioral problems: The Young-HUNT study. Eur Child Adolesc Psychiatry, 24, 503-515.

Tammelin, T., Ekelund, U., Remes, J., Näyhä, S. (2007). Physical activity and sedentary

behaviors among Finnish youth. Med Sci Sports Exerc, 39, 1067-1074. http://doi.org/10.1249/mss.0b13e318058a603

van Gessel, H., Gassmann, J., Kröner-Herwig, B. (2011). Children in pain: Recurrent back pain, abdominal pain, and headache in children and adolescents in a four-year-period. J Pediatr, 158, 977-983. http://doi.org/10.1016/j.jpeds.2010.11.051

Legends for illustrations and tables

Fig 1. Characteristics of clusters by problem range levels (\%) of psychosocial and lifestyle factors among boys.

Fig 2. Characteristics of clusters by problem range levels (\%) of psychosocial and lifestyle factors among girls.

Table 1. Fit statistics for cluster models of one to seven classes, stratified by gender.

Table 2. Demographics of baseline sample.

Table 3. Prevalence of multiple musculoskeletal pain within clusters at the age of 16.

Table 4. Persistence of multiple musculoskeletal pain within clusters of boys and girls aged between 16 and 18. Column per cent and N.

Table 5. Multinomial regression analysis of recurrence of multiple musculoskeletal pain between 16 and 18 years of age within clusters among boys and girls.

This article is protected by copyright. All rights reserved. 
Table 1. Fit statistics for cluster models of one to seven classes, stratified by gender.

\begin{tabular}{|l|l|l|l|l|l|}
\hline $\begin{array}{l}\text { BOYS } \\
\text { (number of classes) }\end{array}$ & BIC & AIC & SSABIC & Entropy & LRT \\
\hline One & 38384.202 & 38310.975 & 38346.073 & N/A & N/A \\
\hline Two & 37902.138 & 37755.683 & 37825.879 & 0.811 & 0.1190 \\
\hline Three & 37609.967 & 37390.284 & 37495.578 & 0.784 & 0.3129 \\
\hline Four & 37568.660 & 37275.750 & 37416.142 & 0.644 & 0.0008 \\
\hline Five & 37603.055 & 37236.918 & 37412.408 & 0.833 & $<0.001$ \\
\hline Six & 37648.546 & 37209.182 & 37419.770 & 0.679 & 0.2307 \\
\hline Seven & 37653.450 & 37140.859 & 37386.545 & 0.822 & 1.0000 \\
\hline $\begin{array}{l}\text { GIRLS } \\
\text { number of classes) }\end{array}$ & & & & \\
\hline One & 26908.612 & 26843.382 & 26870.482 & \\
\hline Two & 25935.439 & 25793.163 & 25862.357 & 0.654 & \\
\hline Three & 25917.237 & 25706.917 & 25809.203 & 0.634 & $<0.0001$ \\
\hline Four & 25606.412 & 25328.046 & 25463.425 & 0.804 & 0.0141 \\
\hline Five & 25641.632 & 25295.221 & 25463.692 & 0.707 & 0.0050 \\
\hline Six & 25669.709 & 25255.253 & 25456.817 & 0.4722 \\
\hline Seven & 25766.152 & 25283.651 & 25518.307 & 0.762 & 0.6387 \\
\hline
\end{tabular}

$\mathrm{AIC}=$ Akaike Information Criteria, $\mathrm{BIC}=$ Bayesian Information Criteria, SSABIC=Sample Size Adjusted Bayesian Information Criteria LRT $=p$-value for the Lo-Mendell-Rubin Likelihood Ratio Test

This article is protected by copyright. All rights reserved. 
Table 2. Demographics of baseline sample.

\begin{tabular}{|c|c|c|}
\hline & $\begin{array}{l}\text { BOYS }(n=3302) \\
\%(n)\end{array}$ & $\begin{array}{l}\text { GIRLS }(n=3590) \\
\%(n)\end{array}$ \\
\hline \multicolumn{3}{|l|}{$\begin{array}{l}\text { Emotional } \\
\text { symptoms }\end{array}$} \\
\hline Problem range & $11(363)$ & $19(700)$ \\
\hline Normal range & 89 (2939) & $81(2890)$ \\
\hline \multicolumn{3}{|l|}{$\begin{array}{l}\text { Behavioural } \\
\text { symptoms }\end{array}$} \\
\hline Problem range & $16(524)$ & $26(931)$ \\
\hline Normal range & $84(2778)$ & $74(2659)$ \\
\hline \multicolumn{3}{|l|}{ Physical activity } \\
\hline$<2$ h/week & $31(1023)$ & 41 (1464) \\
\hline 2-3 h/week & $24(785)$ & $30(1083)$ \\
\hline$>3 \mathrm{~h} /$ week & 45 (1494) & $29(1043)$ \\
\hline \multicolumn{3}{|l|}{ Sitting time } \\
\hline$<4.1 \mathrm{~h} /$ day & $22(730)$ & $30(1082)$ \\
\hline 4.1-7.9 h/day & $43(1427)$ & $43(1548)$ \\
\hline$>7.9$ h/day & $35(1145)$ & $27(960)$ \\
\hline \multicolumn{3}{|l|}{ Weight status } \\
\hline $\begin{array}{l}\text { Normal weight } \\
\text { or underweight }\end{array}$ & $83(2736)$ & $86(3090)$ \\
\hline Overweight & $13(432)$ & $11(387)$ \\
\hline Obese & $4(134)$ & $3(113)$ \\
\hline \multicolumn{3}{|l|}{ Smoking } \\
\hline $\begin{array}{l}\text { No regular } \\
\text { smoking }\end{array}$ & 84 (2767) & $80(2857)$ \\
\hline $\begin{array}{l}0.1-1.0 \text { pack- } \\
\text { year }\end{array}$ & $8(274)$ & $12(445)$ \\
\hline$>1.0$ pack-year & $8(261)$ & $8(288)$ \\
\hline \multicolumn{3}{|l|}{ Sleeping time } \\
\hline$<8 \mathrm{~h} /$ day & $17(552)$ & $25(891)$ \\
\hline
\end{tabular}

This article is protected by copyright. All rights reserved. 


\begin{tabular}{|c|c|c|}
\hline $8-9$ h/day & $66(2198)$ & $65(2330)$ \\
\hline$>9$ h/day & $17(552)$ & $10(369)$ \\
\hline \multicolumn{3}{|l|}{ Family's SES } \\
\hline $\begin{array}{l}\text { Higher clerical } \\
\text { employees }\end{array}$ & 7 (242) & $6(238)$ \\
\hline Self-employed & $17(568)$ & $17(615)$ \\
\hline $\begin{array}{l}\text { Lower clerical } \\
\text { employees }\end{array}$ & $15(493)$ & $15(531)$ \\
\hline Workers & $40(1315)$ & $40(1426)$ \\
\hline Students etc. & $21(684)$ & $22(780)$ \\
\hline \multicolumn{3}{|l|}{ Multiple pains at 16} \\
\hline No pain & $32(1042)$ & $17(595)$ \\
\hline One pain-site & $25(796)$ & $19(675)$ \\
\hline Two pain-sites & $21(660)$ & $24(854)$ \\
\hline Three pain-sites & $13(434)$ & $23(824)$ \\
\hline Four pain-sites & $9(291)$ & $16(578)$ \\
\hline \multicolumn{3}{|l|}{ Multiple pains at 18} \\
\hline No pain & $24(166)$ & $8(71)$ \\
\hline One pain-site & $19(137)$ & $11(101)$ \\
\hline Two pain-sites & $24(167)$ & $21(186)$ \\
\hline Three pain-sites & $19(134)$ & $34(303)$ \\
\hline Four pain-sites & $14(102)$ & $27(242)$ \\
\hline
\end{tabular}

Pack-year $=15$ cigarettes smoked per day for a year

$\mathrm{SES}=$ socioeconomic status

This article is protected by copyright. All rights reserved. 


\begin{tabular}{|c|c|c|c|c|c|c|c|c|}
\hline & \multicolumn{4}{|l|}{ GIRLS } & \multicolumn{4}{|l|}{ BOYS } \\
\hline & $\begin{array}{l}\text { Externalizing } \\
\text { behavior }\end{array}$ & $\begin{array}{l}\text { Multiple } \\
\text { risk } \\
\text { behaviors }\end{array}$ & Obese & Reference & $\begin{array}{l}\text { Externalizing } \\
\text { behavior }\end{array}$ & Sedentary & Obese & Reference \\
\hline & $\%(n)$ & $\%(n)$ & $\%(n)$ & $\%(n)$ & $\%(n)$ & $\%(n)$ & $\%(n)$ & $\%(n)$ \\
\hline $\begin{array}{l}\text { No } \\
\text { pain }\end{array}$ & 9 (44) & $7(31)$ & $13(30)$ & $21(490)$ & $19(88)$ & 34 (294) & $28(70)$ & $36(590)$ \\
\hline $\begin{array}{l}1 \\
\text { pain }\end{array}$ & $15(80)$ & $15(62)$ & $20(46)$ & $21(487)$ & $20(93)$ & $23(200)$ & $25(62)$ & $26(441)$ \\
\hline $\begin{array}{l}2 \\
\text { pains }\end{array}$ & $24(128)$ & $23(95)$ & $27(62)$ & $24(569)$ & $22(98)$ & $21(181)$ & $28(71)$ & $19(310)$ \\
\hline $\begin{array}{l}3-4 \\
\text { pains }\end{array}$ & $52(276)$ & $55(228)$ & $40(93)$ & 34 (805) & 39 (177) & $22(188)$ & $19(48)$ & 19 (312) \\
\hline
\end{tabular}

Table 3. Prevalence of multiple musculoskeletal pain within clusters at the age of 16.

This article is protected by copyright. All rights reserved. 
Table 4. Persistence of multiple musculoskeletal pain within clusters of boys and girls aged between 16 and 18 .

Column per cent and $\mathrm{N}$.

BOYS

$\begin{array}{lll}\text { No pain or one } & \begin{array}{l}\text { No pain or one } \\ \text { pain site at 16, }\end{array} & \text { Multiple pains } \\ \text { pain site at 16 } & \text { multiple pain at } & \text { at } 16 \text { and } 18 \\ \text { and } 18 & 18 & \end{array}$

Externalizing behavior

$32 \%(27)$

$16 \%(13)$

$52 \%(44)$

Sedentary

$37 \%(67)$

$27 \%(50)$

$36 \%(67)$

Obese

$46 \%(22)$

$16 \%(8)$

$38 \%(18)$

Reference

48\% (179)

$27 \%(100)$

$25 \%(96)$

\section{GIRLS}

Externalizing behavior

$12 \%(18)$

$18 \%(25)$

$70 \%(99)$

Multiple risk behaviors

$11 \%(9)$

$18 \%(14)$

$71 \%(56)$

Obese

$18 \%(10)$

$31 \%(17)$

$51 \%(28)$

Reference

$21 \%(132)$

$28 \%(171)$

$51 \%(313)$

This article is protected by copyright. All rights reserved. 
Table 5. Multinomial regression analysis of recurrence of multiple musculoskeletal pain between 16 and 18 years of age within clusters among boys and girls.

\begin{tabular}{|c|c|c|c|c|c|c|c|c|}
\hline \multirow[b]{3}{*}{ Multisite MS pain } & \multicolumn{4}{|c|}{ CLUSTERS OF BOYS } & \multicolumn{4}{|c|}{ CLUSTERS OF GIRLS } \\
\hline & $\begin{array}{l}\text { Externalizing } \\
\text { behavior } \\
\text { OR }(\mathrm{CI})\end{array}$ & $\begin{array}{l}\text { Sedentary } \\
\text { OR (CI) }\end{array}$ & $\begin{array}{l}\text { Obese } \\
\text { OR (CI) }\end{array}$ & $\begin{array}{l}\text { Reference } \\
\text { OR }\end{array}$ & $\begin{array}{l}\text { Externalizing } \\
\text { behavior } \\
\text { OR }(\mathrm{CI})\end{array}$ & $\begin{array}{l}\text { Multiple risk } \\
\text { behaviors } \\
\text { OR (CI) }\end{array}$ & $\begin{array}{l}\text { Obese } \\
\text { OR (CI) }\end{array}$ & $\begin{array}{l}\text { Reference } \\
\text { OR }\end{array}$ \\
\hline & & & & & & & & \\
\hline $\begin{array}{l}\text { Multiple pains at } \\
16 \text { and } 18\end{array}$ & $\begin{array}{l}2.98 \\
(1.73-5.13)\end{array}$ & $\begin{array}{l}\mathbf{1 . 8 5} \\
(1.21-2.82)\end{array}$ & $\begin{array}{l}1.53 \\
(0.78-3.01)\end{array}$ & 1.00 & $\begin{array}{l}2.38 \\
(1.38-4.11)\end{array}$ & $\begin{array}{l}2.73 \\
(1.30-5.71)\end{array}$ & $\begin{array}{l}1.18 \\
(0.55-2.51)\end{array}$ & 1.00 \\
\hline $\begin{array}{l}\text { No pain or one pain } \\
\text { site at } 16 \text {, multiple } \\
\text { pain at } 18\end{array}$ & $\begin{array}{l}0.86 \\
(0.43-1.75)\end{array}$ & $\begin{array}{l}1.34 \\
(0.86-2.09)\end{array}$ & $\begin{array}{l}0.69 \\
(0.29-1.61)\end{array}$ & 1.00 & $\begin{array}{l}1.08 \\
(0.56-2.07)\end{array}$ & $\begin{array}{l}1.25 \\
(0.52-2.98)\end{array}$ & $\begin{array}{l}1.23 \\
(0.54-2.79)\end{array}$ & 1.00 \\
\hline $\begin{array}{l}\text { No pain or one pain } \\
\text { site at } 16 \text { and } 18\end{array}$ & 1.00 & 1.00 & 1.00 & & 1.00 & 1.00 & 1.00 & \\
\hline
\end{tabular}

Adjusted for socioeconomic status

Bolded values are statistically significant

$\mathrm{OR}=$ odds ratio

$\mathrm{CI}=$ confidence interval

Total $\mathrm{N}$ for boys $=691$

Total $\mathrm{N}$ for girls $=892$

This article is protected by copyright. All rights reserved. 
Fig 1. Characteristics of clusters by problem range levels (\%) of psychosocial and lifestyle factors among boys.

\section{BOYS}

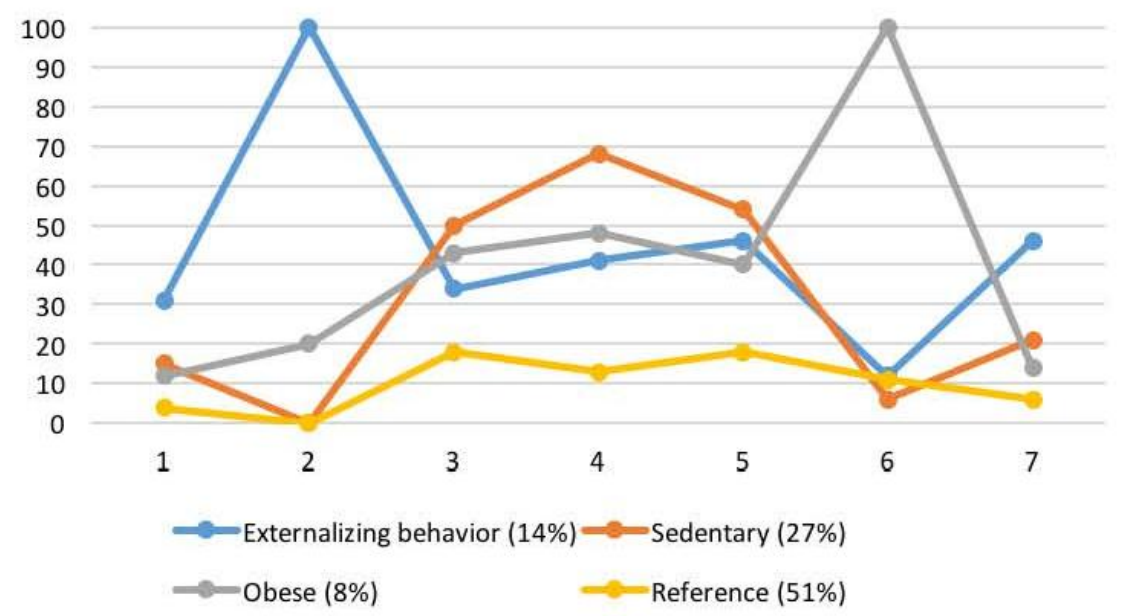

$1=$ internalizing problems $2=$ externalizing problems $3=$ physical activity $<2 \mathrm{~h} /$ week $4=$ sitting time $>8 \mathrm{~h} /$ day

$5=$ detrimental sleeping $(<8 \mathrm{~h}$ or $>9 \mathrm{~h})$

$6=$ overweight/obesity

$7=$ smoking

This article is protected by copyright. All rights reserved. 
Fig 2. Characteristics of clusters by problem range levels (\%) of psychosocial and lifestyle factors among girls.

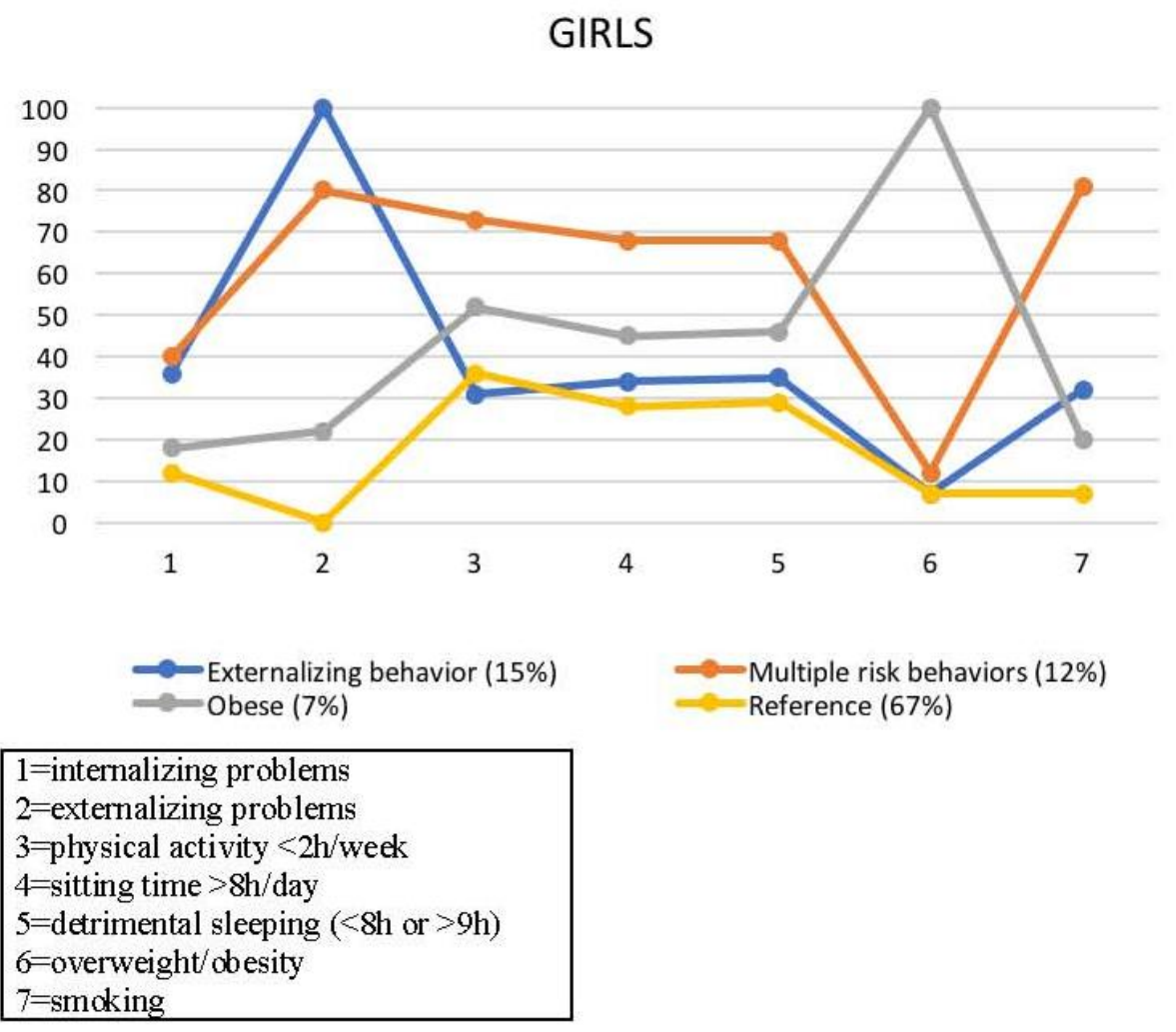

This article is protected by copyright. All rights reserved. 